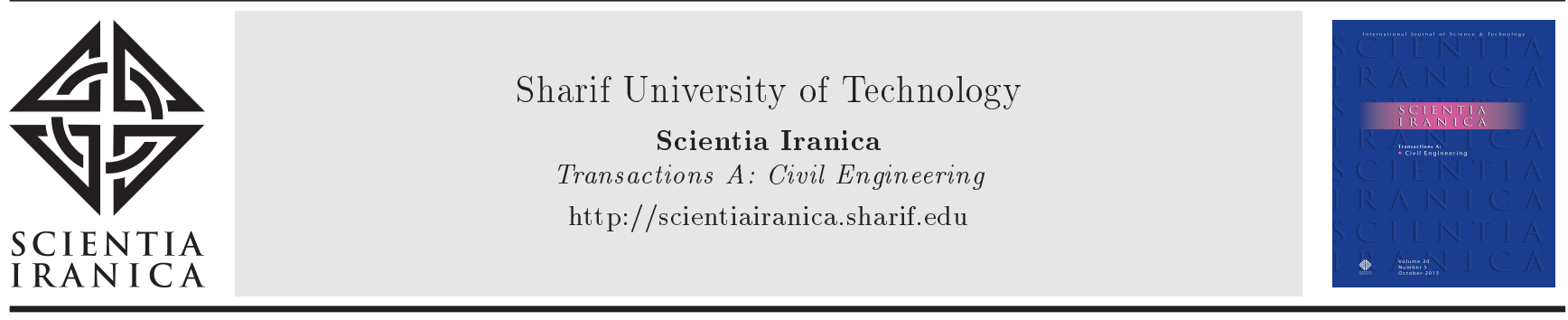

\title{
Effects of recycled polyethylene terephthalate fibers on strength behavior of cemented Babolsar sand
}

\author{
N.R. Malidarreh ${ }^{a}$, I. Shooshpasha ${ }^{b}$, S.M. Mirhosseini ${ }^{a}$, and M. Dehestani ${ }^{b, *}$ \\ a. Department of Civil Engineering, Arak Branch, Islamic Azad University, Arak, Iran. \\ b. Faculty of Civil Engineering, Babol Noshirvani University of Technology, Babol, Iran.
}

Received 30 November 2017; received in revised form 4 April 2018; accepted 2 July 2018

\section{KEYWORDS \\ Direct shear test; \\ Triaxial test; \\ Polyethylene \\ terephthalate fibers; \\ Strength parameters; \\ Reinforced cemented \\ sand.}

\begin{abstract}
Sandy soils constitute a large part of the soils of the northern part of Iran. The construction of structures on these soils will have some problems due to a lack of proper strength properties. On the other hand, in recent years, bottles of polyethylene terephthalate (PET) plastics, such as water and soda bottles, have led to the emergence of an environmental threat due to their prolonged durability in the environment. The utilization of these materials for soil improvement seems to be a sustainable approach. In this research, the effect of recycled PET on the mechanical properties of Babolsar sandy soil is investigated through an extensive experimental analysis carried out using direct shear and Consolidated Drained (CD) triaxial compression tests. Various concentrations of PET were mixed to sand with $3 \%, 5 \%$, and $7 \%$ cement contents. The curing time and relative density of samples were 7 days and $70 \%$, respectively. The results showed that the addition of this fiber improved strength parameters such as cohesion and internal friction angle. Furthermore, the effect of the fiber was not significant with an increase in cement content in samples. The samples with $3 \%$ cement showed better results in both direct shear and triaxial tests. By adding $0.5 \%$ and $1 \%$ PET fibers to the samples containing $3 \%$ cement at $100 \mathrm{kPa}$ pressure, the ratio of strength in direct shear tests increased by $13 \%$ and $24 \%$, respectively, and increased in the triaxial test by $50 \%$ and $93 \%$, respectively.
\end{abstract}

(C) 2020 Sharif University of Technology. All rights reserved.

\section{Introduction}

In recent years, various technical problems have emerged due to the non-principled construction of buildings without considering geotechnical concerns in most areas of the world. One of these concerns is the construction of structures over problematic soils such as loose soil with low strength [1]. On the other hand, the development of the cities and the increasing demand

*. Corresponding author. Tel./Fax: +98 1132331707

E-mail addresses: nimaran@gmail.com (N.R. Malidarreh);

shooshpasha@nit.ac.ir (I. Shooshpasha);

m-mirhoseini@iau-arak.ac.ir (S.M. Mirhosseini);

dehestani@nit.ac.ir (M. Dehestani) for various consumer products require an increase in the production of plastic containers [2]. In this regard, polyethylene terephthalate (PET) is one of the most utilized plastic materials in disposable containers that has attracted much attention because of its unique characteristics [3]. As a result, large amount of PET is added to the urban garbage and may remain there for a long time due to their longer life cycle [4]. However, one of the best solutions for this type of materials is to re-utilize them in various applications.

Soil improvement has proved to be one of the best solutions for enhancing the strength parameters of any problematic soil [5]. In fact, the soil is a kind of material that can normally withstand compressive and shear stresses. However, the problem begins when it is subjected to any tensile stress, which causes failure [6]. 
Consequently, the main objective of soil improvement is to improve shear parameters of the soil in order to increase the tensile strength of the soil.

Various studies have proposed several stabilization techniques to improve the engineering properties of the soil [7-12]. Traditionally, geosynthetics such as geogrid, geotextile, etc. were utilized in various projects for different purposes [13]. Soil reinforcement through the inclusion of oriented or randomly distributed discrete elements such as fibers has recently attracted increasing attention in geotechnical engineering [14]. Recently, randomly distributed fibers have shown a great impact on increasing the en gineering properties of the soil [15-20]. The improvement of the engineering properties (strength, stiffness/modulus, permeability, etc.) of soil with the inclusion of discrete flexible fibers within the soil mass depends on several factors relating to soil characteristics, fiber characteristics, fiber content, distribution and orientation, type of admixtures such as mixing and compaction methods, and test/field conditions [21].

Consoli et al. (1998) carried out extensive laboratory experiments on cemented soil and reinforced it with randomly distributed fibers. They conducted various tests such as triaxial compression tests on the mixture, and found that the brittle behavior of cemented samples changed from brittle to ductile with the addition of fibers. Furthermore, their results revealed that an increase in the amount of fiber caused an increase in both peak and residual strength [22]. Additionally, Consoli et al. in 2003 reported that the failure mechanism of the soil samples was greatly altered by the inclusion of fibers due to the inhibition of tension cracks made by fibers [23]. Further, Consoli et al. investigated the effects of fiber reinforcement on sand with a wide cementation range in 2009. Test results indicated that the addition of cement to sand increased peak strength and brittleness. The fiber reinforcement increases peak strength just up to a certain cement content, increases ultimate strength, and changes the cemented sand brittle behavior to a more ductile one [24]. Hejazi et al. investigated soil reinforcement using natural and synthetic fibers. According to this review, discrete and randomly distributed fiber inclusions significantly increase the peak shear strength, reduce the post-peak strength loss, increase the axial strain to failure, and, in some cases, change the stress-strain behavior from strain softening to strain hardening [25]. Park evaluated unconfined compressive strength and ductility of fiber-reinforced cemented sand. Based on the test results, the inclusion of poly vinyl alcohol fiber has a significant effect on both the unconfined compressive strength and the axial strain at peak strength [26].

PET fibers are one of the randomly distributed fibers that can not only fulfill the aim of soil im- provement, but also eliminate a devastating problem of its disposal in urban areas. Since PET takes a long time to decompose in the environment, it can be the ideal substitute in comparison to the conventional improvement methods. Generally, PET is a light transparent plastic with a density of $1.34 \mathrm{~g} / \mathrm{cm}^{3}$. Its state is shifted from a hard glassy one to a plastic at temperatures over $72^{\circ} \mathrm{C}$ [27-29]. In order to prepare PET fibers, disposable containers, such as water and soda bottles, are gathered from the city and sorted out; then, they are recycled by shredding similarly used containers in the recycling factory. Finally, the shredded parts are melted under a certain condition and turned into fibers $[30,31]$.

The above literature shows that the utilization of randomly distributed fiber can enormously improve soil strength parameters. Besides, the utilization of PET fibers for soil improvement purposes can have some financial and environmental benefits, indicating the significance of investigating their effect on strength parameters. In this study, an intensive laboratory program was carried out in order to thoroughly investigate the effect of added PET fibers on the strength behavior of cemented Babolsar sand. Various amounts of PET fibers were mixed with different samples of various cement contents. Then, direct shear and Consolidated Drained (CD) triaxial tests were performed on all samples. The results are also presented in the current research. Finally, a detailed discussion and a conclusion are provided.

\section{Experimental program}

\subsection{Materials}

In this research, various materials were employed to reach pre-determined objectives. Babolsar sand with a specific gravity rate of 2.74 was utilized as a study soil. It was gathered from the shorelines of the Caspian Sea. Figure 1 shows the particle size distribution curve for this soil carried out according to ASTM D422. The physical and chemical properties of Portland cement (type 3 ) are provided in Table 1. Recycled PET fibers were acquired from Gorgan Industrial Park, Iran. Generally, PET is a transparent lightweight plastic with a density of $1.34 \mathrm{~g} / \mathrm{cm}^{3}$ and is recycled from plastic bottles used for water or soda distribution. Figure 2 presents a picture of the proposed PET, which is $15 \mathrm{~mm}$ long.

\subsection{Methodology}

In this research, the mechanical behavior of the soil was investigated using direct shear and triaxial tests. Direct shear tests were performed at vertical pressures of 50,100 , and $200 \mathrm{kPa}$ using direct shear apparatus with a shear box dimension of $6 \times 6 \mathrm{~cm}$. They were conducted based on ASTM D3080 under CD conditions. 
Triaxial tests were carried out using confining pressures of 50,100 , and $200 \mathrm{kPa}$ over cylindrical specimens with a size of $38 \times 76 \mathrm{~mm}$ (diameter: $38 \mathrm{~mm}$ and height:

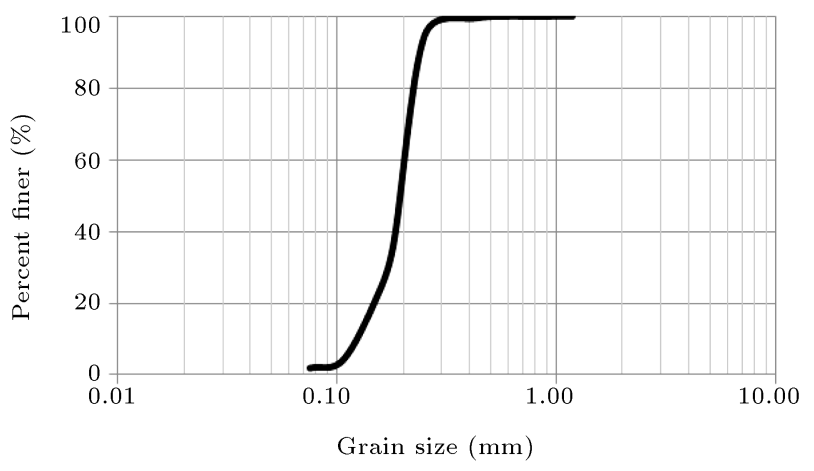

Figure 1. Grain size distribution of Babolsar sand.

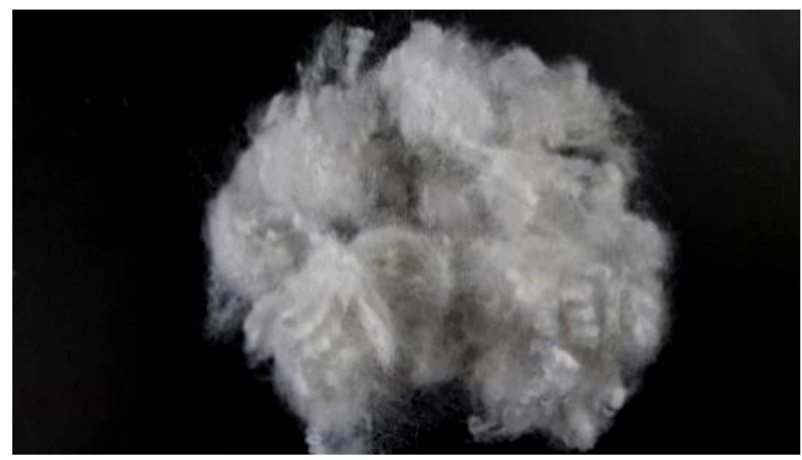

(a)

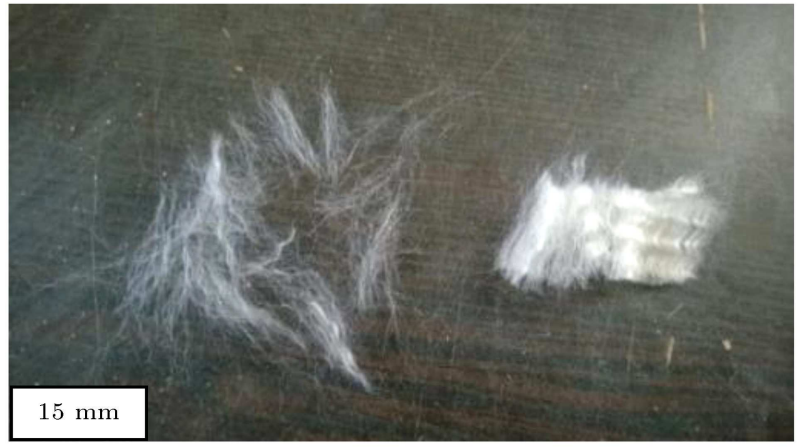

(b)

Figure 2. Polyethylene terephthalate fiber in (a) exterior form used in this research and (b) $15 \mathrm{~mm}$ long sliced form (the length of the white rectangular form as $15 \mathrm{~mm}$ ).

Table 1. Physical and chemical properties of Portland cement type 3 .

\begin{tabular}{lcc}
\hline Compressive strength $\left(\mathrm{kg} / \mathrm{cm}^{2}\right)$ & 7 days & $410 \pm 18$ \\
& 28 days & $500 \pm 19$ \\
Specific gravity $\left(\mathrm{cm}^{2} / \mathrm{gr}\right)$ & & $3.14 \pm 0.2$ \\
Specific surface area $\left(\mathrm{cm}^{2} / \mathrm{gr}\right)$ & $3350 \pm 50$ \\
& & \\
Setting time $(\mathrm{min})$ & Initial & $140 \pm 25$ \\
\hline
\end{tabular}

$76 \mathrm{~mm})$. The triaxial test was initiated by applying the confining pressure to the specimens packed in a membrane; then, it was followed by axially loading the specimen. Similar to the direct shear tests, the triaxial tests were also carried out under a consolidated condition so that comparable results could be obtained.

The samples were prepared through the following procedure: First, cement with weight ratios of 3,5 , and $7 \%$ was added to the soil and $8 \%$ water was mixed with it. Then, PET fibers with ratios of $0,0.5$, and $1 \%$ were combined and blended for 5 minutes using a mixer to form a homogenous mixture. Since all the tests were performed in the dry condition, the specimens were put into the oven at $55^{\circ} \mathrm{C}$ before any testing. Figure 3 shows a picture of the mixture of soil and fiber, and Figure 4 presents a picture of the specimen containing soil and PET prepared for direct shear test. Direct shear specimens were treated in one layer with a relative density rate of $70 \%$ based on the standard method. Then, the prepared specimens were kept for 7 days in thick plastic containers prior to testing. In order to prepare sandy soil specimens for triaxial tests, a new detachable mold (Figure 5) with a diameter of $38 \mathrm{~mm}$ and height of $78 \mathrm{~mm}$ was created.

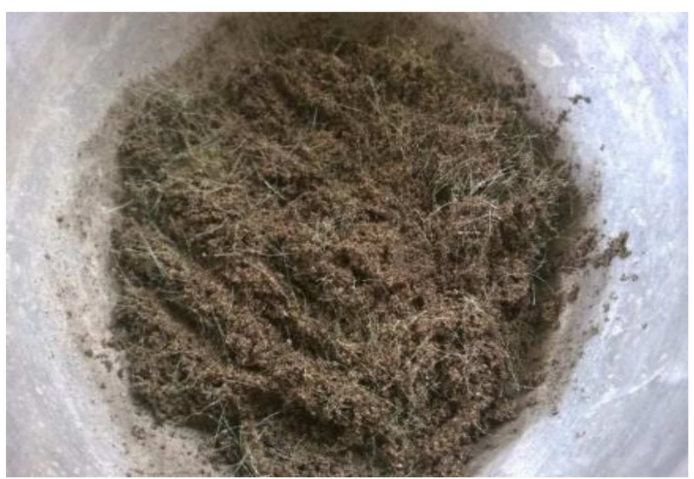

Figure 3. The mixture of cemented sand and Polyethylene terephthalate fibers.

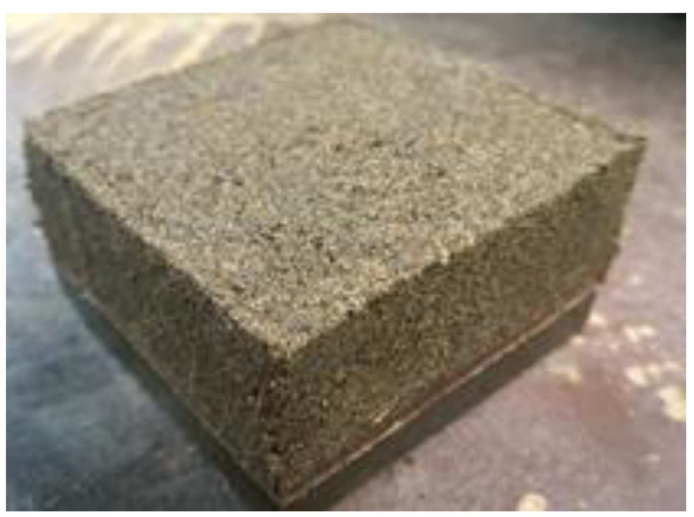

Figure 4. A specimen of polyethylene terephthalate (PET) fibers-reinforced cemented sand prior to direct shear test. 


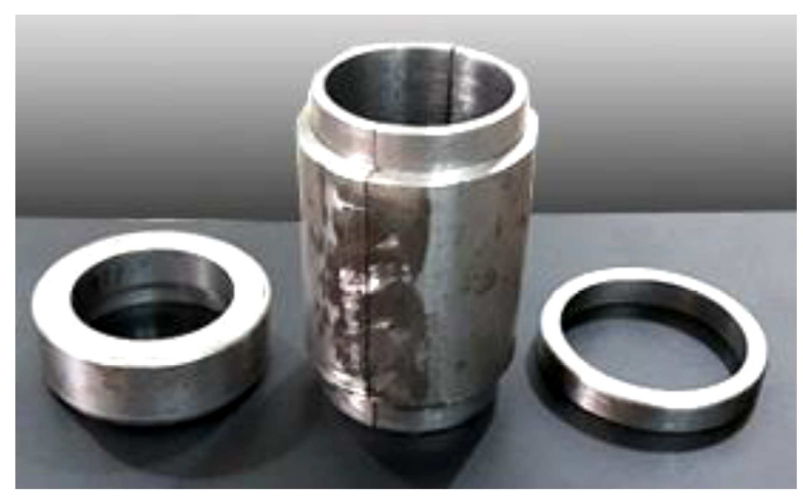

(a)

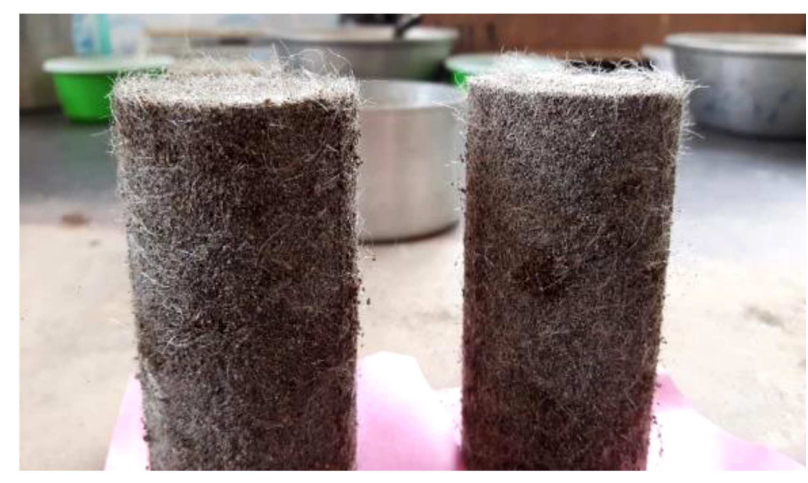

(b)

Figure 5. (a) Created detachable mold for triaxial test. (b) Prepared specimen for triaxial test by using this mold.

Triaxial specimens were treated in three layers with a relative density rate of $70 \%$ based on the standard method. Every sample was put into double layered plastic containers to prevent any moisture loss during treatment. After 7 days of treatment, they were put into the oven for 24 hours to dry.

\section{Results and discussion}

\subsection{Stress-strain curves}

In this section, the behavior of fiber-reinforced cemented sand is evaluated by presenting stress-strain curves obtained from direct shear and CD triaxial tests. Figures 6 to 11 plot stress-strain curves for cemented sand at various percentages of PET fibers and cement at normal and confining pressures of 50, 100, and 200 $\mathrm{kPa}$ in direct shear and triaxial tests.

Generally, these figures demonstrate that reinforcing cemented sand with PET fibers improves the mechanical properties of the sand by increasing maximum strength, residual strength, and failure strain. It is evident that the addition of PET fibers considerably influences the residual strength and the loss of postpeak strength. Cemented samples are mostly inflexible (brittle) due to rapid loss of post-peak strength; however, the addition of PET fibers considerably improves

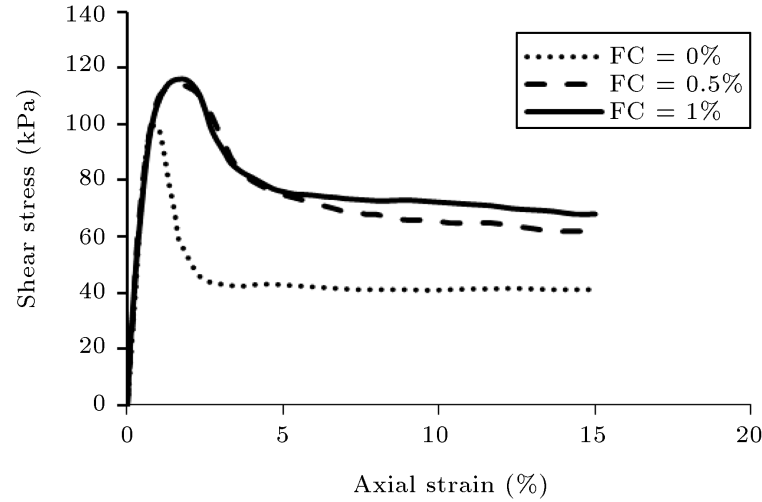

(a)

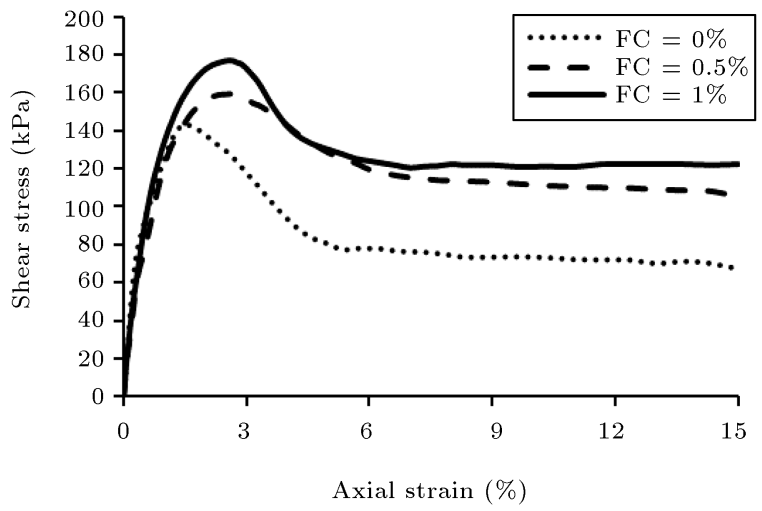

(b)

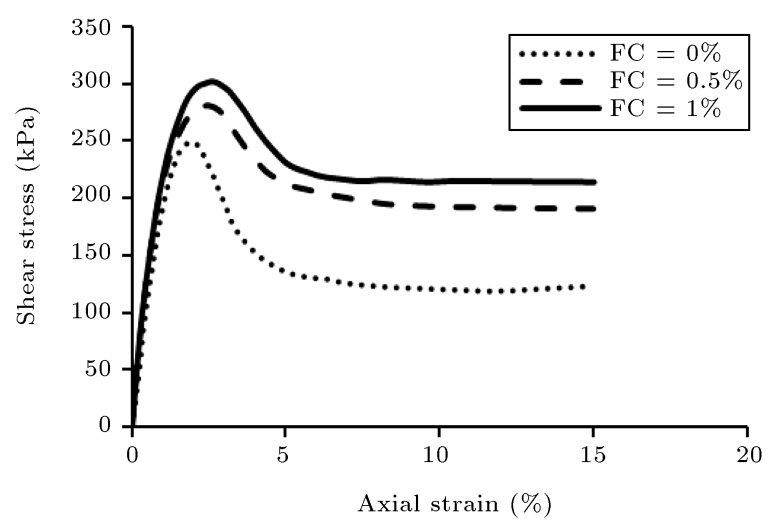

(c)

Figure 6. Stress-strain curve for fiber-reinforced cemented sand with various polyethylene terephthalate (PET) fiber contents and 3\% cement at the normal stress rates of (a) $50 \mathrm{kPa}$, (b) $100 \mathrm{kPa}$, and (c) $200 \mathrm{kPa}$ in the direct shear test.

the flexibility of these samples by decreasing the loss of post-peak strength.

Furthermore, it can be deduced that the effect of PET fibers on the increase of the strength of cemented sand is less signified in contents with a higher amount of cement. In other words, strength difference for a sample with $3 \%$ cement content is more than the corresponding value for a sample with $7 \%$ cement 


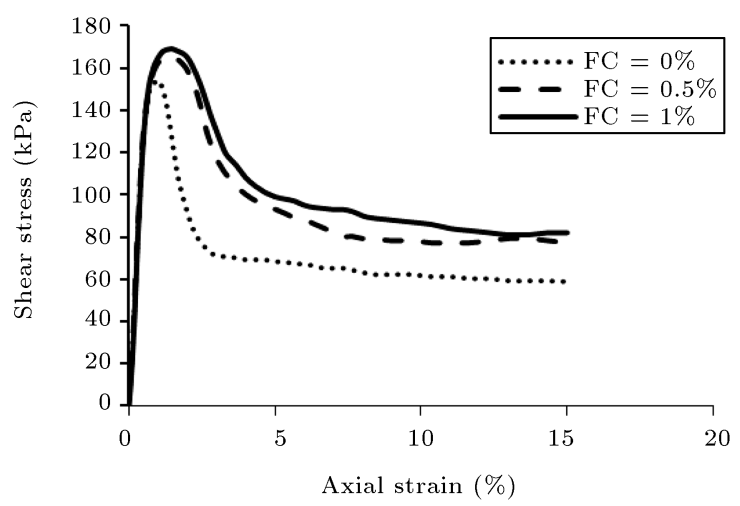

(a)

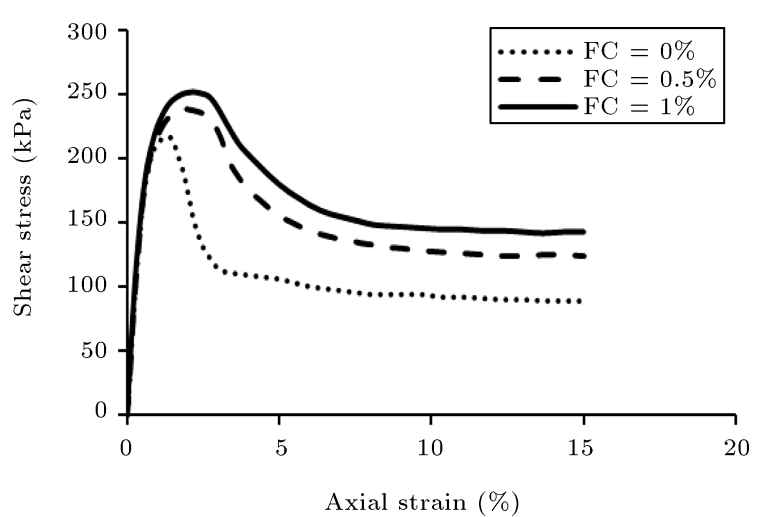

(b)

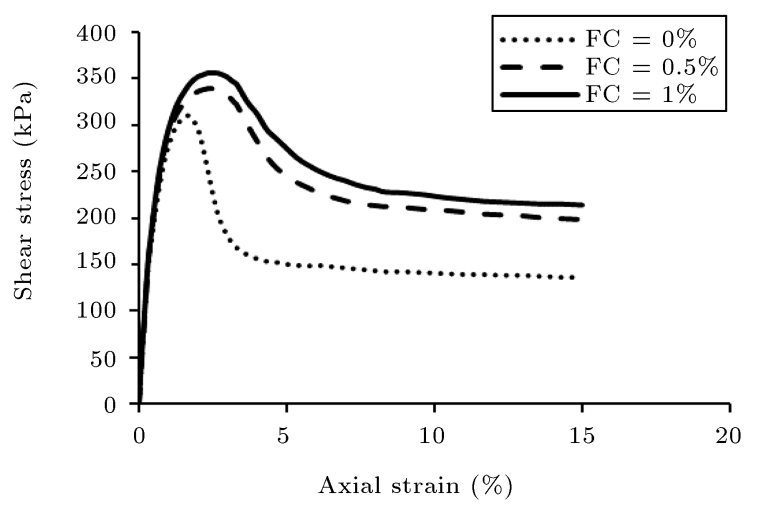

(c)

Figure 7. Stress-strain curve for fiber-reinforced cemented sand with various polyethylene terephthalate (PET) fiber contents and 5\% cement at the normal stress rates of (a) $50 \mathrm{kPa}$, (b) $100 \mathrm{kPa}$, and (c) $200 \mathrm{kPa}$ in the direct shear test.

content. By increasing cement content, soil particles follow each other strongly. Consequently, the strength of the samples significantly increases and the effect of PET fibers on a strength increment diminishes.

Based on the comparison of the results obtained from direct shear and CD triaxial tests, it can be understood that fiber addition affects the results of triaxial tests more than those of the direct shear test. For example, the strength of the fiber-reinforced

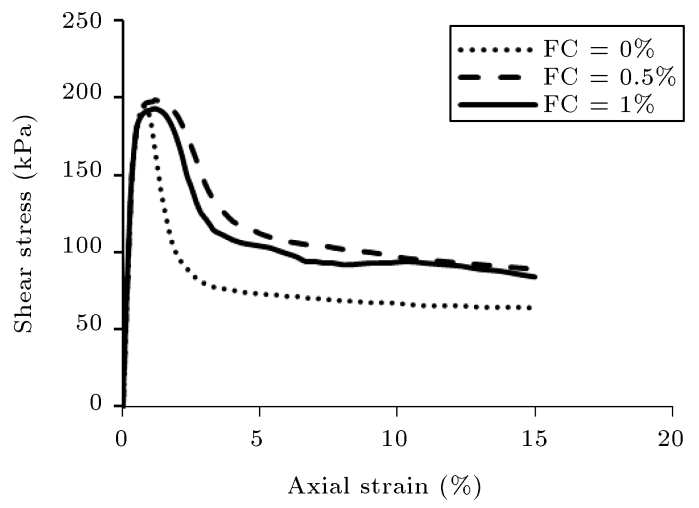

(a)

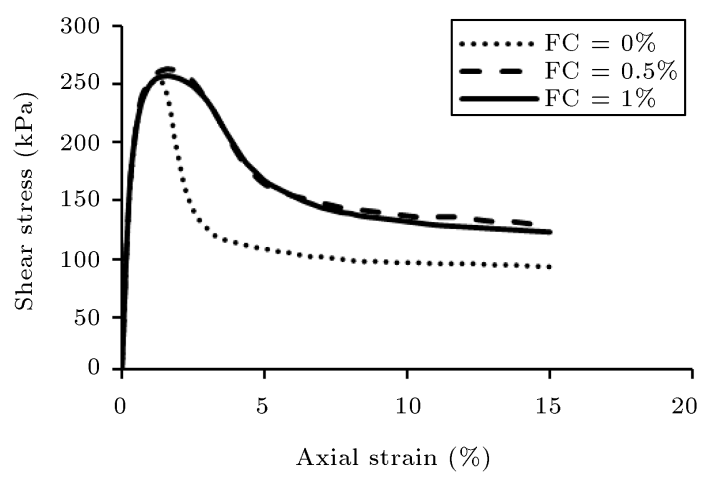

(b)

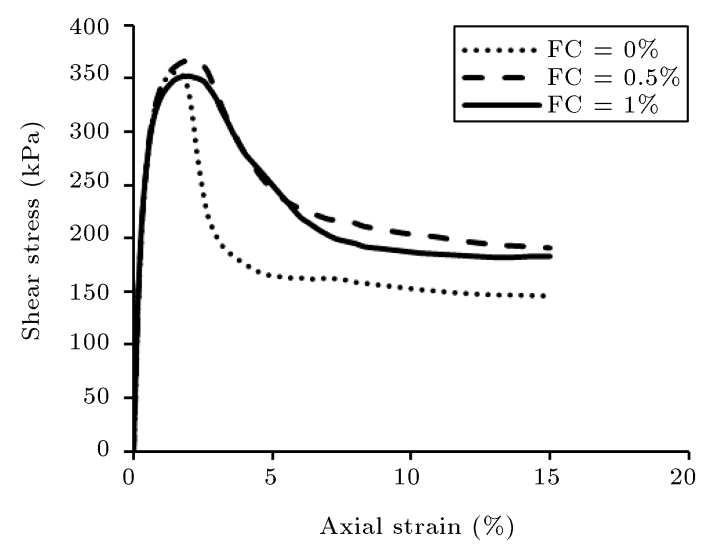

(c)

Figure 8. Stress-strain curve for fiber-reinforced cemented sand with various polyethylene terephthalate (PET) fibers content and $7 \%$ cement at the normal stress rates of (a) $50 \mathrm{kPa}$, (b) $100 \mathrm{kPa}$, and (c) $200 \mathrm{kPa}$ in the direct shear test.

cemented sand sample with a fiber content of $0.5 \%$ at a normal stress of $100 \mathrm{kPa}$ is $13 \%$ more than the corresponding value of the cemented samples without PET fibers, whereas, for the same sample, more than $50 \%$ of strength increment is observed while it is tested by the triaxial apparatus. The reason for this trend can be attributed to the arrangement of the fibers and their corresponding angle toward principal tensile strain directions.

Diambra et al. showed that most of the con- 


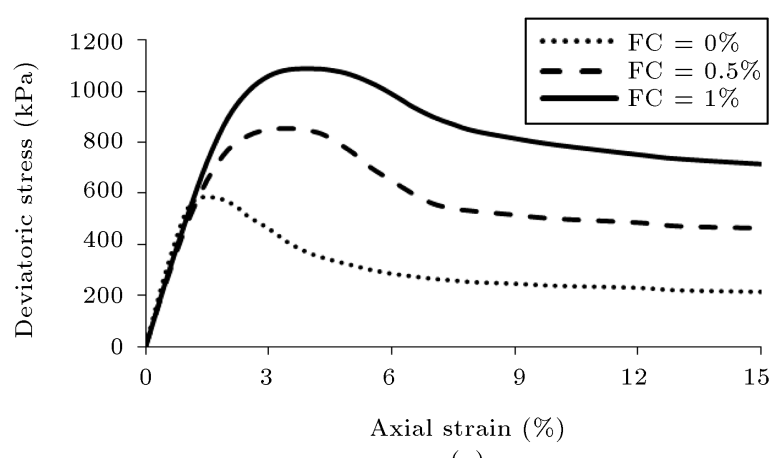

(a)

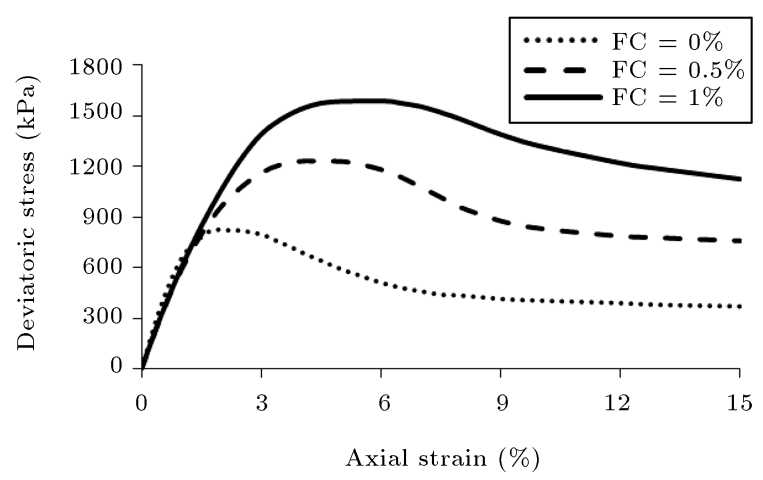

(b)

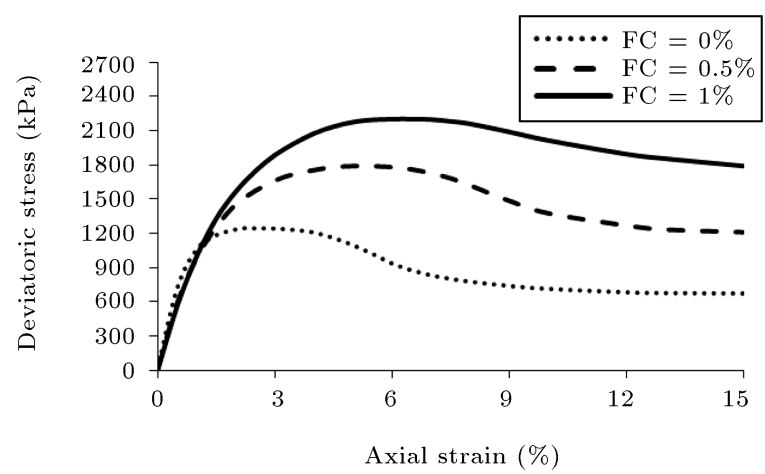

(c)

Figure 9. Stress-strain curve for the fiber-reinforced cemented sand with various polyethylene terephthalate (PET) fiber contents and $3 \%$ cement at the confining pressures of (a) $50 \mathrm{kPa}$, (b) $100 \mathrm{kPa}$, and (c) $200 \mathrm{kPa}$ in the consolidated drained triaxial test.

ventional sample preparation methods, such as wet and dry tamping, could lead to the arrangement of fibers in the horizontal direction [32]. Furthermore, recent studies have shown that stabilizer elements are mostly functional when subjected to tensile strain directions. Jewell showed that the principal tensile strain direction in the direct shear test for dense sand was around 60 degrees above the shear surface [33]. This is also in fair agreement with the findings of the study of Gray and Ohashi, which was carried out using direct shear apparatus on natural and artificial fiber-reinforced sands [34]. Thus, an approximate

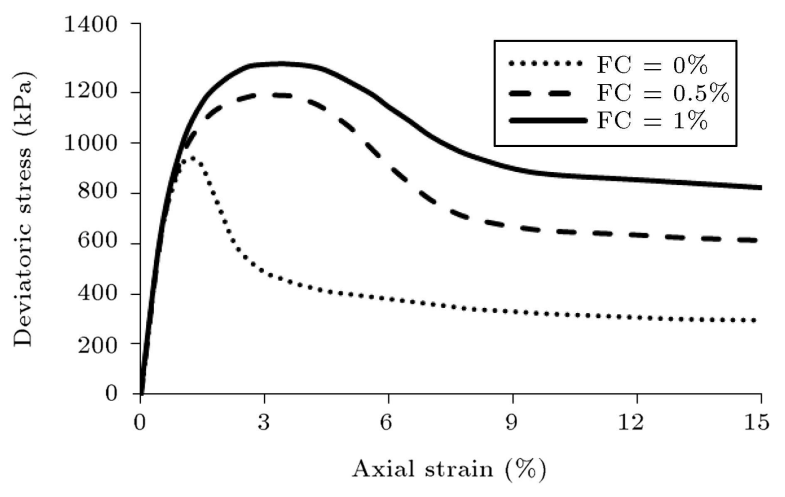

(a)

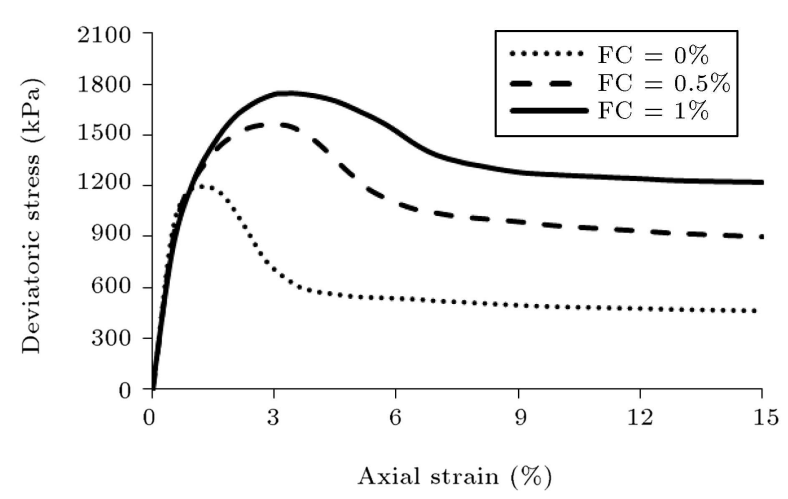

(b)

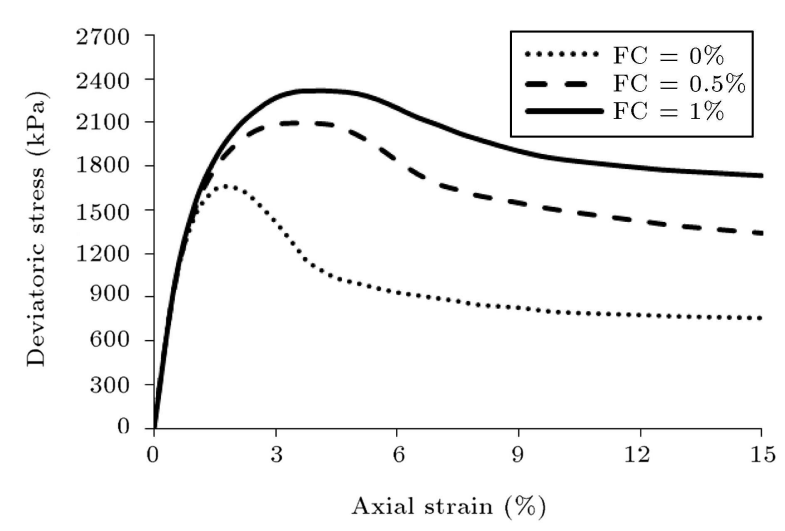

(c)

Figure 10. Stress-strain curve for fiber-reinforced cemented sand with various polyethylene terephthalate (PET) fiber contents and $5 \%$ cement at the confining pressures of (a) $50 \mathrm{kPa}$, (b) $100 \mathrm{kPa}$, and (c) $200 \mathrm{kPa}$ in the consolidated drained triaxial test.

horizontal arrangement of fibers in the direct shear test reduced the efficiency of strength increment due to fiber utilization, and the full potential of the fibers is not utilized. However, in the compressive triaxial test, the direction of the principal tensile strains is horizontal, which aligns with the arrangement of the majority of fibers in the prepared reinforced soil samples using dry tamping method. This yields an increase in the efficiency of fibers on strength increment. 


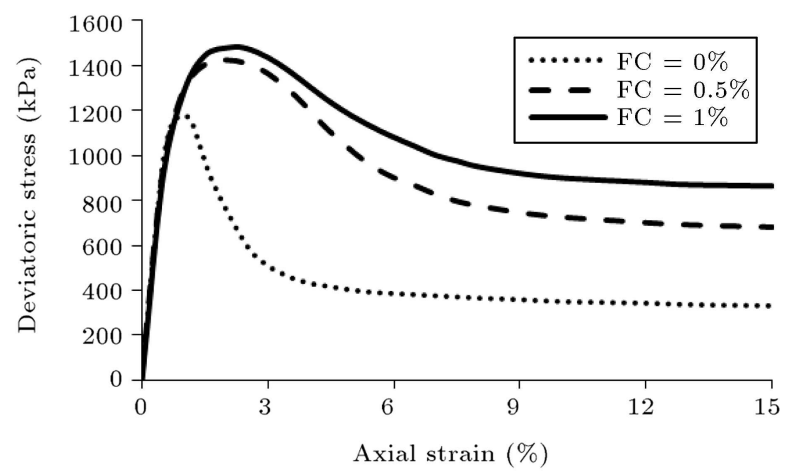

(a)

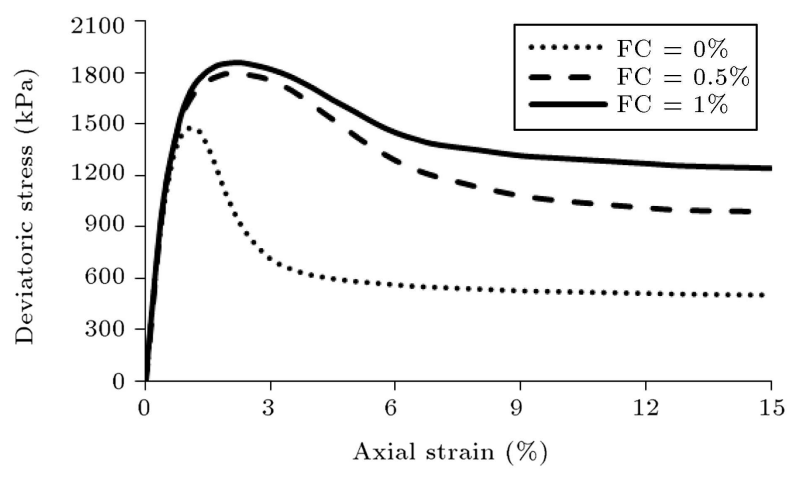

(b)

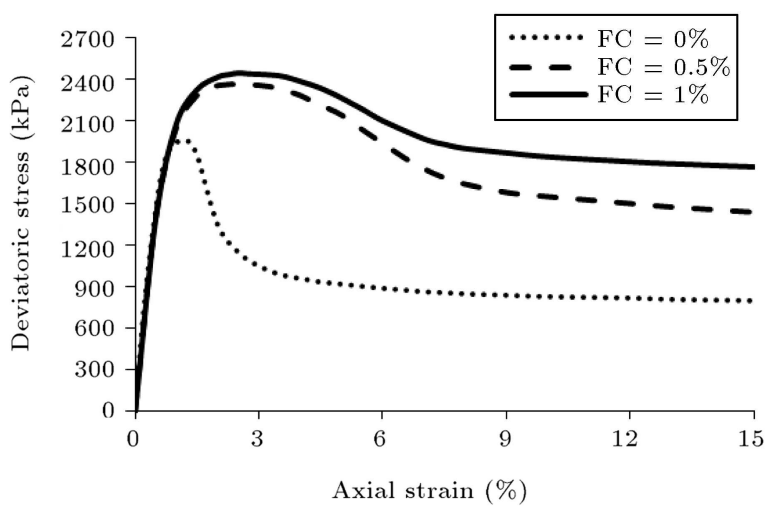

(c)

Figure 11. Stress-strain curve for fiber-reinforced cemented sand with various polyethylene terephthalate (PET) fiber contents and $7 \%$ cement at the confining pressures of (a) $50 \mathrm{kPa}$, (b) $100 \mathrm{kPa}$, and (c) $200 \mathrm{kPa}$ in the consolidated drained triaxial test.

\subsection{Peak strength}

Figures 12 and 13 show deviator stress at failure versus normal pressure or confining pressure for PET fiberreinforced cemented samples at 3 different cement contents tested with direct shear and triaxial apparatuses, respectively. As can be seen, the value of peak strength in the samples with $3 \%$ and $5 \%$ cement contents increases as fiber content increases, which indicates the positive influence of the addition of PET fibers on peak strength increment. However, it can be understood

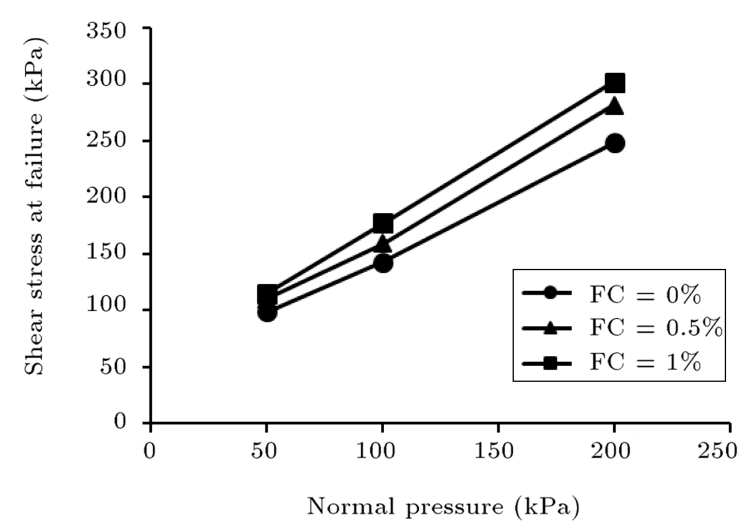

(a)

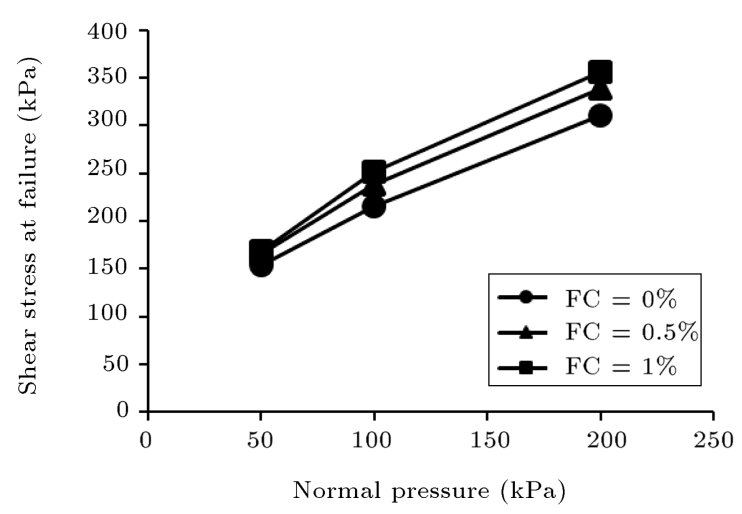

(b)

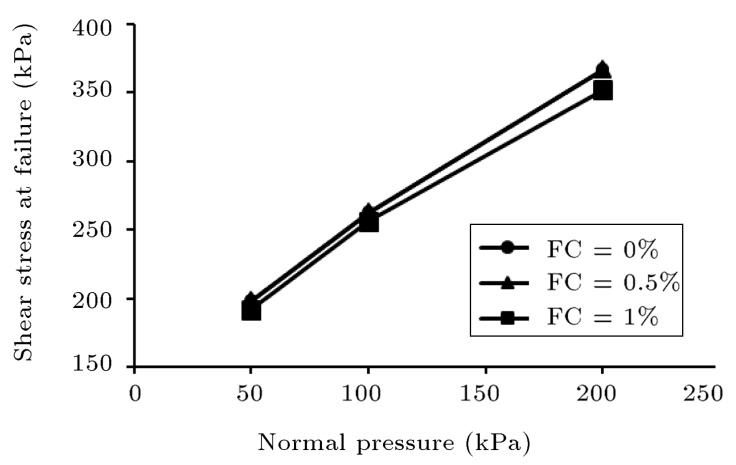

(c)

Figure 12. Peak strength versus normal stress of the fiber-reinforced cemented sand for various polyethylene terephthalate (PET) fiber contents containing (a) 3\%, (b) $5 \%$, and (c) $7 \%$ cement contents in the direct shear test.

that the effect of the addition of $0.5 \%$ PET fibers in the samples with $7 \%$ cement content is more than $1 \%$, since the figure line associated with $0.5 \%$ fiber content stands above the associated line for $1 \%$. Besides, it can be observed that the figure lines are relatively close to each other in direct shear samples with $7 \%$ cement content, indicating that the effect of fiber addition is relatively negligible in these samples.

Unlike the direct shear results where an increase in fiber content at $7 \%$ cement content yields a reduction 
in peak strength (according to Figures 8 and 12(c)), an increase in peak strength is observed for all cement contents with an increase in fiber content in triaxial test results. However, with an increase in cement content (especially in $7 \%$ cement content), the effect of fiber addition on peak strength is reduced. A short distance between the plots associated with $0.5 \%$ and $1 \%$ fibers in Figure 13(c) indicates that, in samples containing $7 \%$ cement, no impressive increment in the samples with $3 \%$ and $5 \%$ cement is observed.

As Consoli et al. [24] mentioned in their study, the addition of cement to the sand significantly increased

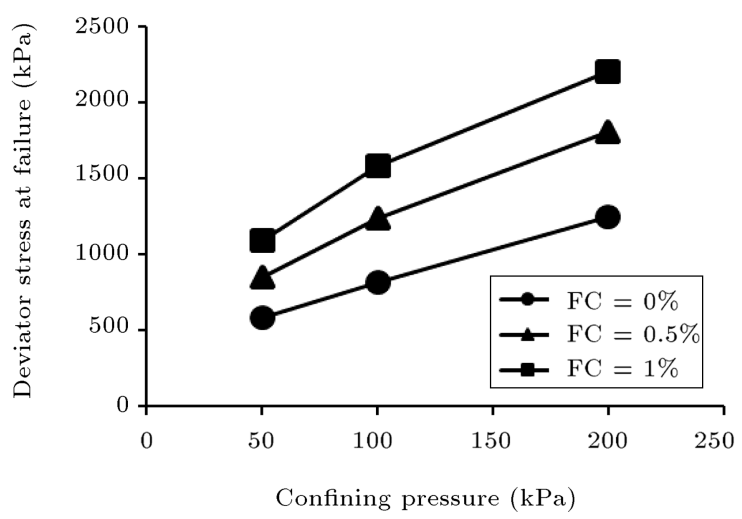

(a)

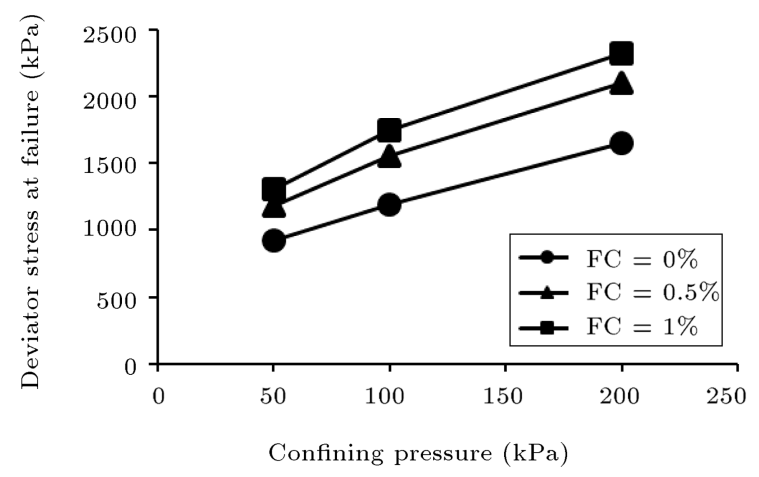

(b)

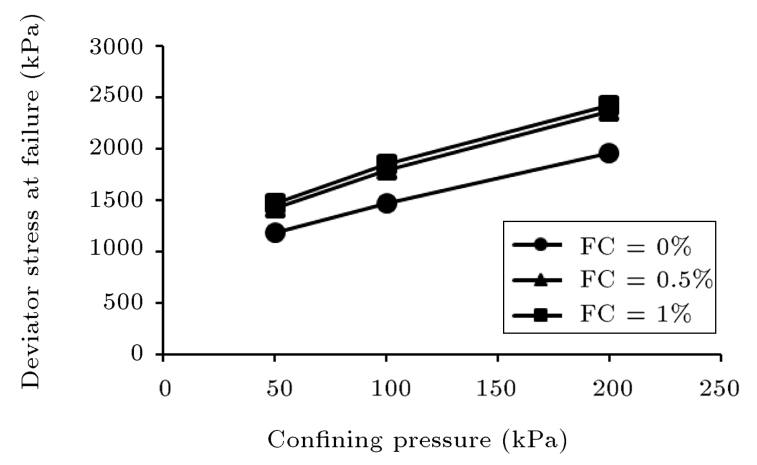

(c)

Figure 13. Peak strength versus normal stress of fiber-reinforced cemented sand for various polyethylene terephthalate (PET) fibers contents containing (a) 3\%, (b) $5 \%$, and (c) $7 \%$ cement in the consolidated drained triaxial test. peak strength in contents up to $10 \%$ by weight of dry sand; the same result was achieved in this study.

\subsection{Residual strength}

The residual strength is the strength that a soil shows after failure and, generally, the strength associated with $15 \%$ of strain is considered as the residual strength. In this section, the brittleness index is defined as an indicator of soil flexibility. It is the ratio of the difference between peak strength and residual strength over peak strength.

Figure 14 plots the brittleness index versus normal pressure for reinforced cemented sand at different PET fiber contents containing 3, 5, and $7 \%$ cements

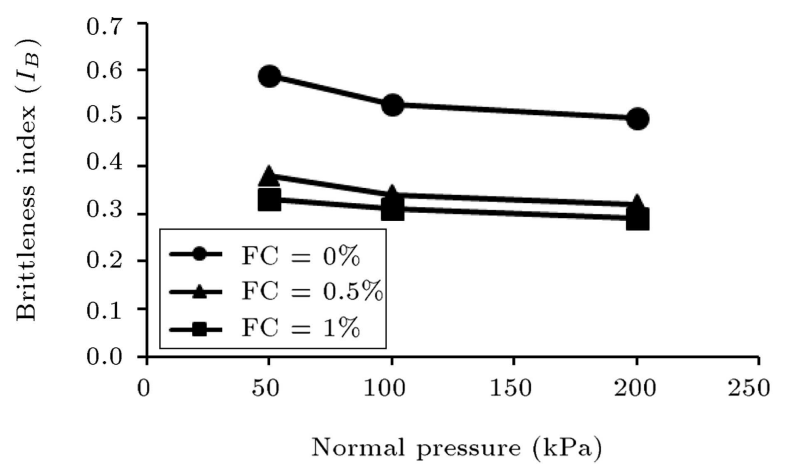

(a)

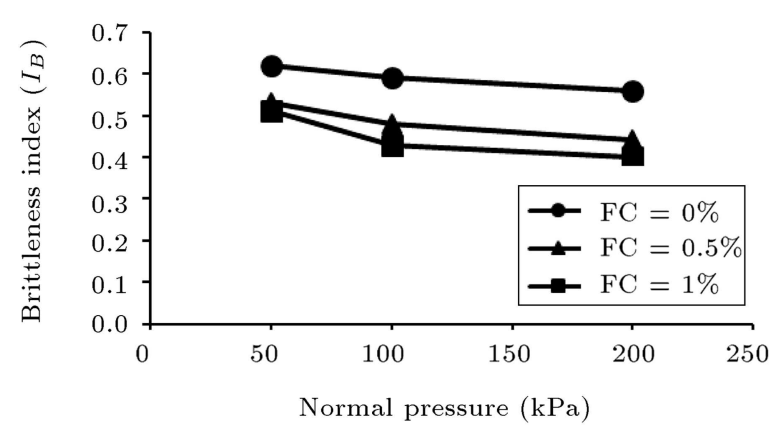

(b)

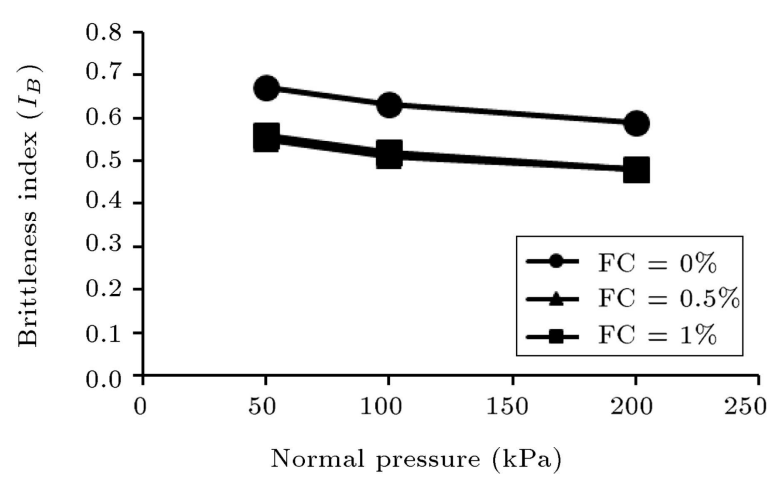

(c)

Figure 14. Effect of the addition of polyethylene terephthalate (PET) fibers on brittleness index in samples containing (a) $3 \%$, (b) $5 \%$, and (c) $7 \%$ cement in the direct shear test. 


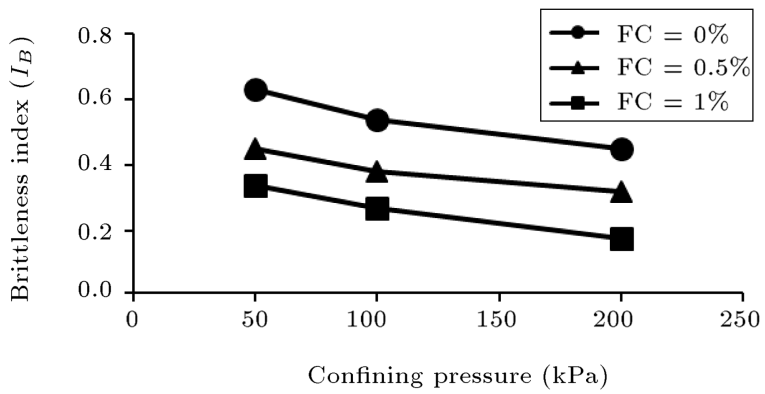

(a)

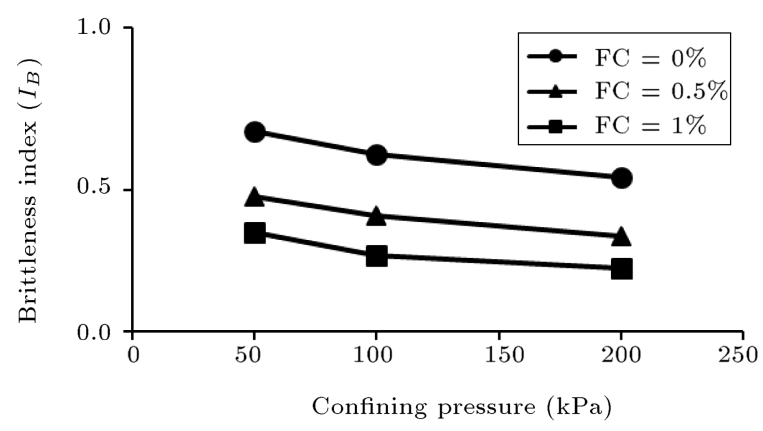

(b)

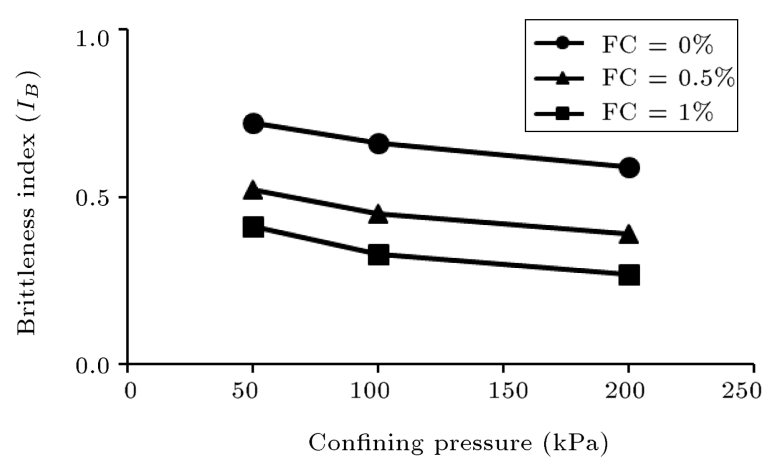

(c)

Figure 15. Effect of the addition of polyethylene terephthalate (PET) fibers on brittleness index in samples containing (a) $3 \%$, (b) $5 \%$, and (c) $7 \%$ cement in the consolidated drained triaxial test.

tested with the direct shear apparatus. Besides, Figure 15 plots the same information for the samples tested in the CD triaxial condition. It can be observed that with an increase in fiber content and normal pressure or confining pressure, the value of the brittleness index decreases. For example, the value of the brittleness index for the cemented sample without PET fibers under $100 \mathrm{kPa}$ normal stress tested with direct shear apparatus is 0.53 , which is greater than the corresponding values of reinforced cemented samples with $0.5 \%(0.34)$ and $1 \%(0.31)$ PET fibers contents. Similarly, the cemented samples without PET fibers tested with the triaxial apparatus at the confining pressure of $100 \mathrm{kPa}$ acquire a brittleness index of 0.55 , while the brittleness index for the reinforced samples with $0.5 \%$ and $1 \%$ fiber contents is 0.38 and 0.27 , respectively.
Additionally, similar to the study results of other researchers [24,35], it can be understood that the samples become more brittle as the cement content increases. However, the addition of PET fibers shows considerable effect by increasing residual strength, which yields a reduction in the brittle index. For instance, the brittleness index for the samples containing 3, 5, and $7 \%$ cements tested with the direct shear apparatus under $100 \mathrm{kPa}$ normal stress is 0.53 , 0.59 , and 0.63 , respectively, while the values of the reinforced samples with $1 \%$ fiber content are 0.31 , 0.43 , and 0.52 , respectively. These values indicate that unlike what was observed for peak strength, the effect of fiber addition on the brittleness index does not significantly decrease as the cement content increases. For example, a $1 \%$ increase in fiber content in the sample containing $7 \%$ cement is unlikely to influence peak strength adversely; it shows a positive influence.

\subsection{Failure strain}

Failure strain is another parameter that is very important in cemented soils with brittle behavior. The presence of randomly distributed fibers in cemented soil can yield an increase in flexibility of the soil and the strain corresponding to the failure.

Table 2 presents various values of failure strains for PET fibers-reinforced cemented samples corresponding to different normal pressures. In this table, sample names starting with "DS" correspond to the samples tested with the direct shear apparatus. However, "T" relates to the samples tested under the drained consolidated triaxial condition. Additionally, the numbers denote cement contents.

With an increase in PET fiber contents and normal pressure or confining pressure, it can be observed that failure strain increases in both sample types. Besides, an increase in failure strain in triaxial samples is noticeably more than what is observed in direct shear samples. Stress-strain curves plotted for the reinforced samples tested by direct shear apparatus showed no significant difference in the initial hardening behavior of samples. Consequently, an increase in failure strain can be attributed to an increase in peak strength.

A noticeable point is that the hardening of the samples increases by increasing cement content, which in turn leads to a reduction in failure strain regarding the samples with $5 \%$ cement content in comparison to the samples with $3 \%$ cement content despite an increase in peak strength. For example, the failure strain of direct shear samples without PET fibers and 3\% cement content under $100 \mathrm{kPa}$ normal pressure is $1.51 \%$. However, this value is $1.38 \%$ for a sample containing $5 \%$ cement content tested under the same condition. Similarly, failure strain for reinforced samples with $5 \%$ cement content is less than the corresponding value of the reinforced sample with $3 \%$ cement content. The 
Table 2. Failure strain variation in polyethylene terephthalate (PET) fibers-reinforced cemented samples containing 3, 5, and $7 \%$ cement based on direct shear and consolidated drained triaxial test results.

\begin{tabular}{|c|c|c|c|c|c|c|c|}
\hline \multirow{2}{*}{$\begin{array}{c}\text { PET fiber } \\
\text { content (\%) }\end{array}$} & \multirow{2}{*}{$\begin{array}{c}\text { Initial pressure } \\
(\mathbf{k P a})^{*}\end{array}$} & \multicolumn{6}{|c|}{ Failure strain (\%) } \\
\hline & & DS-3** & $\mathbf{T}-3^{* *}$ & DS-5** & $\mathbf{T}-5^{* *}$ & DS- $7^{* *}$ & $\mathbf{T}-\mathbf{7}^{* *}$ \\
\hline \multirow{3}{*}{0} & 50 & 0.83 & 1.31 & 0.74 & 1.02 & 0.65 & 0.72 \\
\hline & 100 & 1.51 & 1.8 & 1.38 & 1.48 & 1.22 & 1.04 \\
\hline & 200 & 1.83 & 2.23 & 1.69 & 1.82 & 1.52 & 1.26 \\
\hline \multirow{3}{*}{0.5} & 50 & 1.41 & 3.62 & 1.27 & 2.65 & 1.08 & 1.55 \\
\hline & 100 & 1.95 & 4.45 & 1.89 & 3.1 & 1.58 & 1.91 \\
\hline & 200 & 2.67 & 5.23 & 2.48 & 3.91 & 2.21 & 2.24 \\
\hline \multirow{3}{*}{1} & 50 & 1.49 & 4.12 & 1.39 & 2.81 & 0.98 & 1.62 \\
\hline & 100 & 2.13 & 5.67 & 1.98 & 3.24 & 1.54 & 2.1 \\
\hline & 200 & 2.75 & 6.25 & 2.56 & 3.98 & 2.06 & 2.29 \\
\hline
\end{tabular}

reason could be attributed to the discussed reduction of fiber addition efficiency in the case of higher cement contents.

However, the effect of fiber content in a sample with $7 \%$ cement yielded a reduction in failure strain, compared with samples containing $3 \%$ and $5 \%$ cements. For example, an increase in fiber content from $0 \%$ to $0.5 \%$ in samples tested with direct shear apparatus under $50 \mathrm{kPa}$ normal stress shifts failure strain in samples with $3 \%, 5 \%$, and $7 \%$ cement contents from $0.83 \%$ to $1.41 \%, 0.74 \%$ to $1.27 \%$, and $0.65 \%$ to $1.08 \%$, respectively.

Furthermore, it can be understood that the effect of the addition of PET fibers in failure strain in samples with higher cement content is lower than that in other samples in triaxial tests. For instance, the value of failure strain under $100 \mathrm{kPa}$ confined pressure for samples with $3 \%, 5 \%$, and $7 \%$ cement contents is $1.8 \%$, $1.48 \%$, and $1.04 \%$, respectively. The reinforcement of these samples with $0.5 \%$ PET fibers modifies the failure strain values to $4.45 \%, 3.10 \%$, and $1.91 \%$, respectively. It is shown that the percentage of an increase in failure strain due to reinforcement is $2.65 \%, 1.62 \%$, and $0.87 \%$ for samples with $3 \%, 5 \%$, and $7 \%$ cement contents, respectively, indicating a reducing trend of failure strain increment by increasing the cement content.

\subsection{Strength parameters}

In this section, strength parameters such as internal friction angle $(\varphi)$ and cohesion $(C)$ are investigated. Figures 16 and 17 indicate the failure envelopes of PET fiber-reinforced cemented sand in direct shear and CD triaxial tests, respectively. Tables 3 and 4 show internal friction angle and cohesion for the PET fiberreinforced cemented samples tested by direct shear and triaxial tests. Generally, an increase in PET fiber content yields an increase in internal friction angle and cohesion. The only exception is the sample with $0.5 \%$ fiber content tested with direct shear apparatus (DS7 ), which has a higher value than that of the sample with $1 \%$ fiber content. The reason for this trend can be attributed to the lower efficiency of PET fibers in samples with $7 \%$ cement content, as discussed previously.

Furthermore, it can be observed that an increase in cement content reduces the amount of increment in the internal friction angle. For example, in the direct shear tests, the addition of $0.5 \%$ PET fibers increases the internal friction angle to 4,3 , and 1 degrees in samples with $3 \%, 5 \%$, and $7 \%$ cement contents, respectively. This indicates a reducing pattern by the addition of PET fibers in the internal friction angle due to an increment in cement content, roughly showing the adverse effect of cement addition on the internal friction angle in higher cement contents. Additionally, it can be seen that the value of cohesion increases as PET fiber content increases. However, in samples with $7 \%$ cement content, the value of cohesion decreases by increasing fiber content from $0.5 \%$ to $1 \%$ in all samples tested with direct shear and triaxial apparatuses.

\subsection{Mechanism of failure}

The cemented sand samples without PET fibers under shear loading failed instantly, considered as a diagonal line in the specimens. By adding fibers, the behavior of specimens changed from brittle to ductile, where buckling appeared in the samples (shown in Figure 18). An increase in the amount of cement caused an increase in the brittleness of the samples. At the same time, the efficiency of the fibers in the samples with a higher percentage of cement $(5 \%$ and $7 \%$ ) decreased. Generally, with an increase in the amount of fibers and cement, the specimens become more ductile and brittle, respectively. 


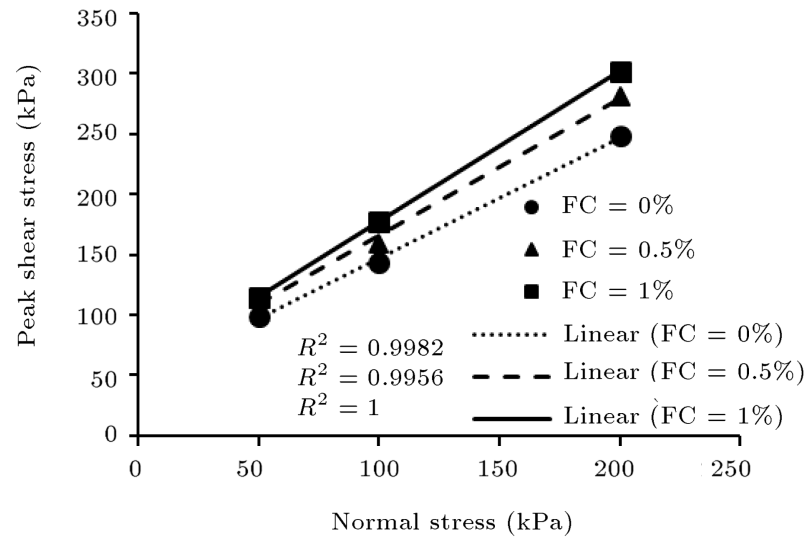

(a)

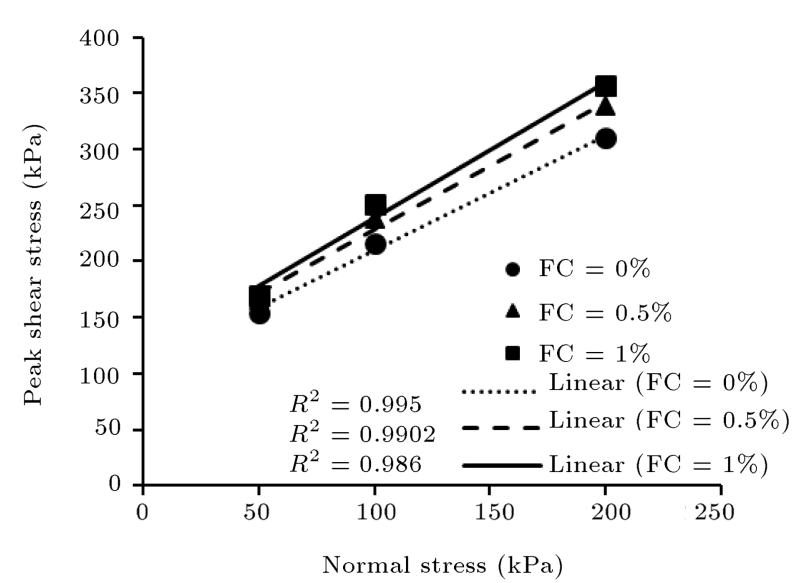

(b)

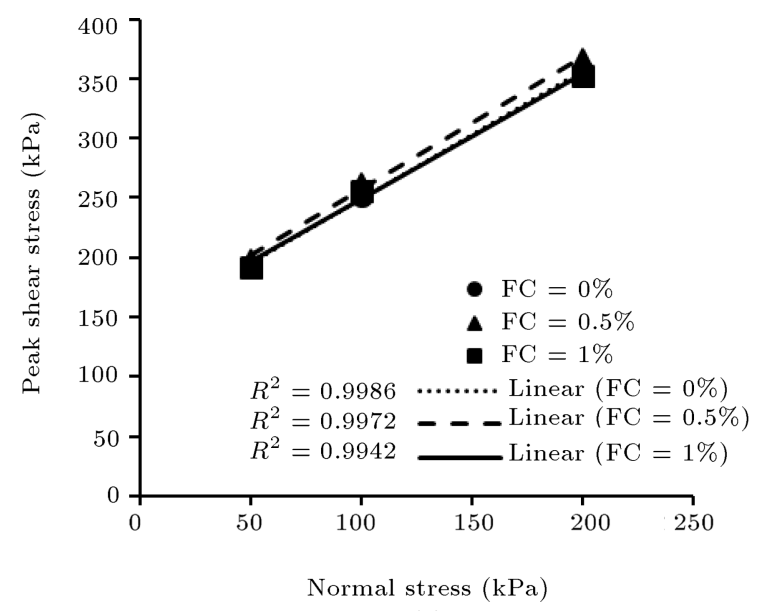

(c)

Figure 16. Failure envelopes of polyethylene terephthalate (PET) fiber-reinforced cemented sand containing (a) $3 \%$, (b) $5 \%$, and (c) $7 \%$ cement in the direct shear test.

\section{Conclusion}

The following conclusions are made based on the obtained results:

- Reinforcing cemented sand with PET fibers improved the mechanical properties of the sand by

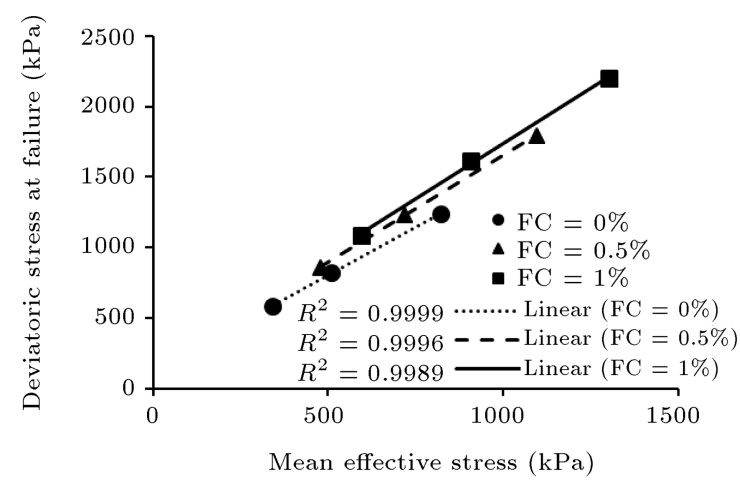

(a)

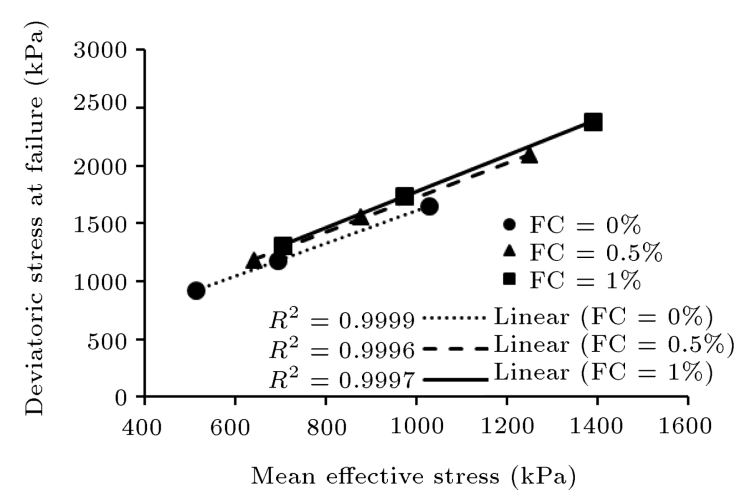

(b)

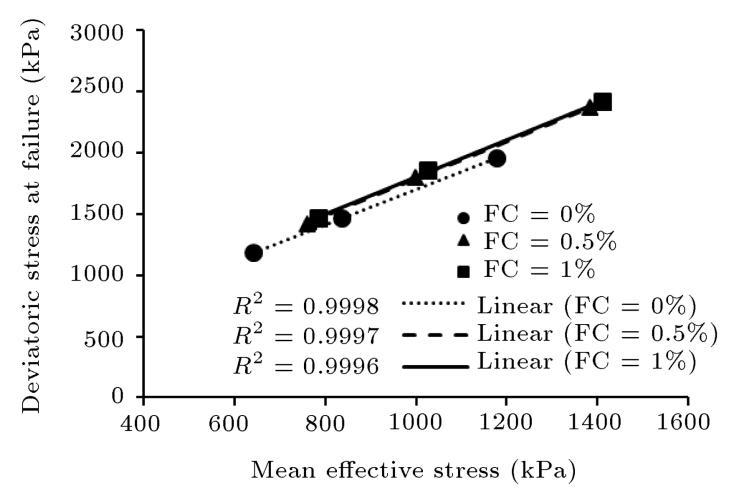

(c)

Figure 17. Failure envelopes of polyethylene terephthalate (PET) fiber-reinforced cemented sand containing (a) $3 \%$, (b) $5 \%$, and (c) $7 \%$ cement in the consolidated drained triaxial test.

increasing maximum strength, residual strength, and failure strain;

- Generally, the samples containing 3\% cement and $1 \%$ fibers showed better results in strength parameters than other samples. The samples with $3 \%$ cement showed better results in both direct shear and triaxial tests. By adding $0.5 \%$ and $1 \%$ PET fibers to the samples containing 3\% cement at $100 \mathrm{kPa}$ pressure, the ratio of strength in direct shear tests increased by $13 \%$ and $24 \%$, respectively; in the triaxial test, it increased by $50 \%$ and $93 \%$, respectively; 
Table 3. Internal friction angle for polyethylene terephthalate (PET) fiber-reinforced cemented samples.

\begin{tabular}{ccccccc}
\hline \multirow{2}{*}{$\begin{array}{c}\text { PET fiber } \\
\text { content (\%) }\end{array}$} & \multicolumn{5}{c}{ Internal friction angle (Deg) } \\
\cline { 2 - 7 } & $\mathbf{D S}^{*} \mathbf{- 3}$ & $\mathbf{T}^{*} \mathbf{- 3}$ & $\mathbf{D S}^{*} \mathbf{- 5}$ & $\mathbf{T}^{*} \mathbf{- 5}$ & $\mathbf{D S}^{*} \mathbf{- 7}$ & $\mathbf{T}^{*} \mathbf{- 7}$ \\
\hline 0 & 45 & 43 & 46 & 45 & 47 & 46 \\
0.5 & 49 & 50 & 49 & 49 & 48 & 49 \\
1 & 51 & 52 & 51 & 51 & 46 & 50 \\
\hline
\end{tabular}

* DS and T denote the samples tested with direct shear and consolidated drained triaxial apparatuses, respectively. Numbers show cement content.

Table 4. Cohesion for polyethylene terephthalate (PET) fiber-reinforced cemented samples.

\begin{tabular}{ccccccc}
\hline \multirow{2}{*}{$\begin{array}{c}\text { PET fiber } \\
\text { content (\%) }\end{array}$} & \multicolumn{6}{c}{ Cohesion (kPa) } \\
\cline { 2 - 7 } & $\mathbf{D S}^{*} \mathbf{- 3}$ & $\mathbf{T}^{*} \mathbf{- 3}$ & $\mathbf{D S}^{*} \mathbf{- 5}$ & $\mathbf{T}^{*} \mathbf{- 5}$ & $\mathbf{D S}^{*} \mathbf{- 7}$ & $\mathbf{T}^{*} \mathbf{- 7}$ \\
\hline 0 & 47 & 77 & 107 & 140 & 141 & 186 \\
0.5 & 52 & 98 & 115 & 164 & 147 & 204 \\
1 & 54 & 123 & 117 & 167 & 144 & 211 \\
\hline
\end{tabular}

* DS and T denote the samples tested with direct shear and consolidated drained triaxial apparatuses, respectively. Numbers show cement content.

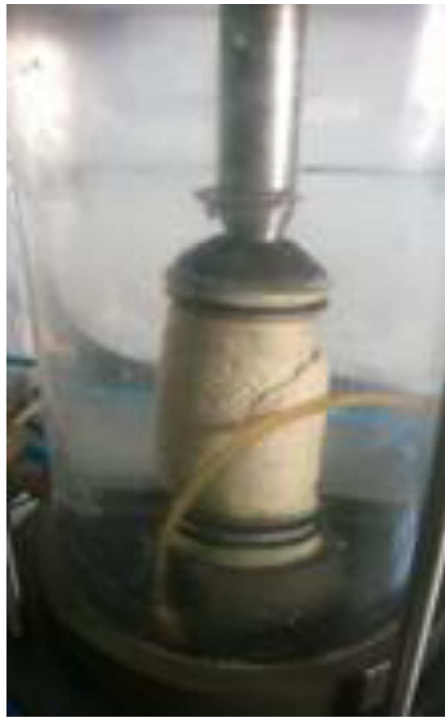

Figure 18. Buckled specimen after failure.

- The effect of PET fibers was less marked with an increase in cement content in samples. By increasing the cement content, soil particles followed each other strongly. Consequently, the strength of the samples significantly increased and the effect of PET fibers on a strength increment was diminished. In other words, the difference in strength for a sample with $3 \%$ cement content was greater than that for a sample with $7 \%$ cement content;

- The addition of PET fibers affected the results of triaxial tests in comparison to the results of the direct shear test because of the arrangement of the fibers and their corresponding angle toward principal tensile strain directions;
- Cemented samples were mostly inflexible (brittle) due to the rapid loss of post-peak strength and, by increasing cement content, the samples became more brittle; however, the addition of PET fibers considerably improved the flexibility of these samples and showed a significant effect by increasing residual strength that resulted in a reduction in the brittle index;

- With an increase in PET fiber contents and normal pressure or confining pressure, failure strain increased. Besides, an increase in failure strain in triaxial samples was noticeably more than what was observed in direct shear samples;

- An increase in PET fiber content led to an increase in the internal friction angle and cohesion. The only exception is the sample with $0.5 \%$ fiber content and $7 \%$ cement content tested with direct shear apparatus, which is characterized by a higher value than the sample with $1 \%$ fiber content. The reason for this trend can be attributed to the lower efficiency of PET fibers in samples with $7 \%$ cement content.

\section{References}

1. Baynes, F.J. "Sources of geotechnical risk", Quarterly Journal of Engineering Geology and Hydrogeology, 43(3), pp. 321-331 (2010).

2. Gürü, M., Çubuk, M.K., Arslan, D., Farzanian, S.A., and Bilici, I. "An approach to the usage of polyethylene terephthalate (PET) waste as roadway pavement material", Journal of Hazardous Materials, 279, pp. 302-310 (2014).

3. Ameri, M. and Nasr, D. "Performance properties of devulcanized waste PET modified asphalt mixtures", 
Petroleum Science and Technology, 35(1), pp. 99-104 (2017).

4. Gironi, F. and Piemonte, V. "Life cycle assessment of polylactic acid and polyethylene terephthalate bottles for drinking water", Environmental Progress \& Sustainable Energy, 30(3), pp. 459-468 (2011).

5. Van Impe, W.F., Soil Improvement Techniques and Their Evolution, Taylor \& Francis (1989).

6. Das, B.M. and Sivakugan, N. "Fundamentals of geotechnical engineering", Cengage Learning, 5th Edn. (2016).

7. Ahmad, F., Bateni, F., and Azmi, M. "Performance evaluation of silty sand reinforced with fibres", Geotextiles and Geomembranes, 28(1), pp. 93-99 (2010).

8. Changizi, F. and Haddad, A. "Strength properties of soft clay treated with mixture of nano-SiO2 and recycled polyester fiber", Journal of Rock Mechanics and Geotechnical Engineering, 7(4), pp. 367-378 (2015).

9. Chen, M., Shen, S.L., Arulrajah, A., Wu, H.N., Hou, D.W., and Xu, Y.S. "Laboratory evaluation on the effectiveness of polypropylene fibers on the strength of fiber-reinforced and cement-stabilized Shanghai soft clay", Geotextiles and Geomembranes, 43(6), pp. 515523 (2015).

10. Gelder, C. and Fowmes, G.J. "Mixing and compaction of fibre-and lime-modified cohesive soil", Proceeding of the Institution of Civil Engineers, Ground Improvement, 169(GI2), pp. 98-108 (2015).

11. Indraratna, B., Chu, J., and Rujikiatkamjorn, C., Ground Improvement Case Histories: Chemical, Electrokinetic, Thermal and Bioengineering, Elsevier Science (2015).

12. Sivakumar Babu, G.L. and Chouksey, S.K. "Analytical model for stress-strain response of plastic waste mixed soil", Journal of Hazardous, Toxic, and Radioactive Waste, 16(3), pp. 219-228 (2011).

13. Biabani, M.M. and Indraratna, B. "An evaluation of the interface behaviour of rail subballast stabilised with geogrids and geomembranes", Geotextiles and Geomembranes, 43(3), pp. 240-249 (2015).

14. Anagnostopoulos, C.A., Tzetzis, D., and Berketis, K. "Shear strength behaviour of polypropylene fibre reinforced cohesive soils", Geomechanics and Geoengineering, 9(3), pp. 241-251 (2014).

15. Anggraini, V., Asadi, A., Huat, B.B., and Nahazanan, H. "Effects of coir fibers on tensile and compressive strength of lime treated soft soil", Measurement, 59, pp. 372-381 (2015).

16. Botero, E., Ossa, A., Sherwell, G., and OvandoShelley, E. "Stress-strain behavior of a silty soil reinforced with polyethylene terephthalate (PET)", Geotextiles and Geomembranes, 43(4), pp. 363-369 (2015).

17. Falorca, I.M.C.F.G. and Pinto, M.I.M. "Effect of short, randomly distributed polypropylene microfibres on shear strength behaviour of soils", Geosynthetics International, 18(1), pp. 2-11 (2011).
18. Hamidi, A. and Hooresfand, M. "Effect of fiber reinforcement on triaxial shear behavior of cement treated sand", Geotextiles and Geomembranes, 36, pp. 1-9 (2013).

19. Malidarreh, N.R., Shooshpasha, I., Mirhosseini, S.M., and Dehestani, M. "Effects of reinforcement on mechanical behaviour of cement treated sand using direct shear and triaxial tests", International Journal of Geotechnical Engineering, 12(5), pp. 1-9 (2017).

20. Noorzad, R. and Amini, P.F. "Liquefaction resistance of Babolsar sand reinforced with randomly distributed fibers under cyclic loading", Soil Dynamics and Earthquake Engineering, 66, pp. 281-292 (2014).

21. Shukla, S.K., Fundamentals of Fibre-Reinforced Soil Engineering, Springer (2017).

22. Consoli, N.C., Prietto, P.D., and Ulbrich, L.A. "Influence of fiber and cement addition on behavior of sandy soil", Journal of Geotechnical and Geoenvironmental Engineering, 124(12), pp. 1211-1214 (1998).

23. Consoli, N.C., Casagrande, M.D., Prietto, P.D., and Thomé, A.N. "Plate load test on fiber-reinforced soil", Journal of Geotechnical and Geoenvironmental Engineering, 129(10), pp. 951-955 (2003).

24. Consoli, N.C., Vendruscolo, M.A., Fonini, A., and Dalla Rosa, F. "Fiber reinforcement effects on sand considering a wide cementation range", Geotextiles and Geomembranes, 27(3), pp. 196-203 (2009).

25. Hejazi, S.M., Sheikhzadeh, M., Abtahi, S.M., and Zadhoush, A. "A simple review of soil reinforcement by using natural and synthetic fibers", Construction and Building Materials, 30, pp. 100-116 (2012).

26. Park, S.S. "Unconfined compressive strength and ductility of fiber-reinforced cemented sand", Construction and Building Materials, 25(2), pp. 1134-1138 (2011).

27. Bach, C., Dauchy, X., Severin, I., Munoz, J.F., Etienne, S., and Chagnon, M.C. "Effect of temperature on the release of intentionally and non-intentionally added substances from polyethylene terephthalate (PET) bottles into water: Chemical analysis and potential toxicity", Food Chemistry, 139(1), pp. 672-680 (2013).

28. Shotyk, W. and Krachler, M. "Contamination of bottled waters with antimony leaching from polyethylene terephthalate (PET) increases upon storage", Environmental Science \& Technology, 41(5), pp. 1560-1563 (2007).

29. Steiner, G. and Zimmerer, C. "Polyethylene terephthalate (PET)", In Polymer Solids and Polymer MeltsDefinitions and Physical Properties I, Springer Berlin Heidelberg, pp. 772-779 (2013).

30. Awaja, F. and Pavel, D. "Recycling of PET", European Polymer Journal, 41(7), pp. 1453-1477 (2005).

31. Jankauskaite, V., Macijauskas, G., and Lygaitis, R. "Polyethylene terephthalate waste recycling and application possibilities: a review", Mater Sci (Medžiagotyra), 14(2), pp. 119-127 (2008). 
32. Diambra, A., Russell, A.R., Ibraim, E., and Muir Wood, D. "Determination of fibre orientation distribution in reinforced sands", Géotechnique, $\mathbf{5 7}(7)$, pp. 623-628 (2007).

33. Jewell, R.A. "Some factors which influence the shear strength of reinforced sand", Technical Report, University of Cambridge, Department of Engineering, 85 (1980).

34. Gray, D.H. and Ohashi, H. "Mechanics of fiber reinforcement in sand", Journal of Geotechnical Engineering, 109(3), pp. 335-353 (1983).

35. Consoli, N.C., Vendruscolo, M.A., Fonini, A., and Dalla Rosa, F. "Fiber reinforcement effects on sand considering a wide cementation range", Geotextiles and Geomembranes, 27(3), pp. 196-203 (2009).

\section{Biographies}

Nima R. Malidarreh received MSc in Geotechnical Engineering at the Department of Civil Engineering, Mazandaran University, Mazandaran, Iran in 2007 and obtained his $\mathrm{PhD}$ in Geotechnical Engineering from Islamic Azad University, Arak Branch, Arak, Iran in 2016. His research interests are in the fields of soil improvement and environmental geotechnics.

Issa Shoshpasha is an Associated Professor at the
Department of Civil Engineering at Noshorvani University of Technology, Mazandaran, Babol, Iran. He received $\mathrm{MSc}$ and $\mathrm{PhD}$ in Geotechnical Engineering from McGill University, Montreal, Canada in 1993 and 1996, respectively. His research interests are in the fields of bearing capacity of shallow and deep foundation, soil improvement, unsaturated soil, slope stability, and liquefaction.

Seyed Mohamad Mirhosseini is an Assistant Professor at the Department of Civil Engineering at Islamic Azad University, Arak Branch, Arak, Iran. He received MSc in Civil Engineering and Structural Engineering from Ferdowsi University of Mashhad, Iran in 2008 and PhD in the same field of study from Science and Research Branch of Islamic Azad University, Tehran, Iran in 2013. His research interests include the fields of structural and earthquake engineering.

Mehdi Dehestani is an Associated Professor at the Department of Civil Engineering at Noshorvani University of Technology, Mazandaran, Babol, Iran. He received $\mathrm{MSc}$ and $\mathrm{PhD}$ in Civil Engineering and Structural Engineering from Sharif University of Technology, Tehran, Iran in 2006 and 2010, respectively. His research interests are in the fields of structural and geotechnical engineering. 